\title{
Analisis Pengolahan Citra Mri Otak Menggunakan Segmentasi Watershed Dengan Filter Sobel Dan Morphological Gradient
}

\author{
Khoerun Nisa Syaja'ah ${ }^{\text {* }}$, Yudha Satya Perkasa ${ }^{1}$ \\ ${ }^{1}$ Jurusan Fisika, Fakultas Sains dan Teknologi UIN Sunan Gunung \\ Djati Bandung \\ *Email : khoerunnisasya@gmail.com
}

\begin{abstract}
ABSTRAK
Pencitraan medis atau medical imaging adalah suatu cara untuk mendapatkan informasi citra medis tanpa harus menggunakan tindakan operasi atau bedah. Proses diagnosis dalam pencitraan medis akan memberikan informasi terkait bentuk, lokasi, objek yang di teliti, atau disebut dengan ROI (Region of Interest). Pada Penelitian ini dibuat sebuah rancangan metoda segmentasi secara komputasi menggunakan teknik watershed dengan filter sobel dan morphological gradient untuk menganalisis daerah tumor dan mengurangi efek segmentasi berlebihan yang muncul pada teknik watershed, pada citra otak dengan tinjauan tiga slice hasil citra MRI yang berbeda yaitu axial, koronal dan sagital. Hasil percobaan dari dua metoda kombinasi teknik watershed makers dan morphological gradient menghasilkan segmentasi baik mengurangi segmentasi yang berlebihan serta hasil yang lebih tajam, dengan hasil pengujian kualitas citra dengan metoda SNR (Signal Noise to Ratio) untuk setiap slice adalah axial $5.73 \mathrm{~dB}$, koronal $6.38 \mathrm{~dB}$ dan sagital $5.96 \mathrm{~dB}$ dengan waktu rata-rata komputasi adalah $1.20 \mathrm{~s}$ dan kombinasi segmentasi menggunakan filter sobel untuk masing-masing slice adalah axial $5.68 \mathrm{~dB}$, koronal $6.28 \mathrm{~dB}$, dan sagital $5.27 \mathrm{~dB}$ dengan waktu rata-rata komputasi adalah1.80 s.
\end{abstract}

Kata kunci: Segmentasi; Watershed; Sobel;Morphological Gradient; SNR

\begin{abstract}
Medical imaging is a way to get the medical image without using surgery. The process of diagnosis in medical imaging will provide
\end{abstract}


information regarding the shape, location, objects in conscientious, or ROI (Region of Interest). In this research created a design method of segmentation computation using the technique watershed with filter Sobel and morphological gradient to analyze the region of the tumor and reduce the effects of segmentation excessive appearing on technique watershed, the image of the brain from three slice results MRI axial, coronal and sagittal planes. The experimental results of the two methods combination of techniques and morphological gradient watershed makers produce better segmentation reduces excessive segmentation and image are sharper than segmentation using Sobel filter, with image quality results SNR (Signal Noise to Ratio) for each slice is $5.73 \mathrm{~dB}$ axial, coronal and sagittal $6.38 \mathrm{~dB} 5.96 \mathrm{~dB}$ average time computing is $1.20 \mathrm{~s}$ and the combination of segmentation using Sobel filter for each slice is $5.68 \mathrm{~dB}$ axial, coronal $6.28 \mathrm{~dB}$, and sagittal $5.27 \mathrm{~dB}$ with an average time of computing adalah1.80 s.

Key Words : Segmentation; Watershed; Sobel; Morphological Gradient; SNR

\section{Pendahuluan}

Tumor otak dapat berasal dari elemen saraf pada jaringan otak. Tumor otak ini sifatnya primer ataupun merupakan metastasis. Gangguan yang ditimbulkan dari kanker atau tumor otak ini bisa merusak saraf pusat pada otak dan mengakibatkan kerusakan sistem saraf koginitif. Berdasarkan data yang dihimpun International Agency for Research on Cancer lebih dari 126.000 orang di dunia mengidap tumor otak tiap tahun dan lebih diantaranya 97.000 meninggal [1]. Beberapa hal terkait tumor ini sulit untuk di lihat secara visual karena pada umumnya batas tumor tidak jelas apalagi jika masih di stadium awal, kekontrasanya tidak jelas dan bahkan terkadang mirip dengan jaringan normal. Proses Segmentasi saat ini masih banyak dilakukan secara manual selain hasilnya yang sangat objektif dan waktu yang digunakannya cukup lama [6], untuk mengurangi permasalahan ini sistem pencitraan medis pada penelitian ini menggunakan teknik segmentasi watershed dengan uji coba filter sobel dan morphological gradient yang mempunyai keunggulan 
dalam mendeteksi tepi menggunakan persamaan sobel dan identifikasi gradient menggunakan matematika morphologi. Segmentasi citra yaitu teknik pengelompokan (clustering) untuk kata lain pengelompokan citra kedalam wilayah tertentu yang diinginkan atau mempunyai kesamaan fitur antara lain : tingkat keabuan (grayscale), teksture, warna, atau gerakan [8]. Metoda watershed adalah salah satu cara segmentasi citra yang membagi citra menjadi region yang berbeda. Pada dasarnya teknik watershed memiliki prinsip seperti air [9]. Dengan cara menggambarkan citra sebagai relief topografi, pertama kali dikenalkan oleh Beucheur dan Meyer pada tahun 1993. Dari proses ini akan dihasilkan 3 titik yang diasumsikan sebagai langkah penting dalam proses segmentasi[5][10].

a) Titik daerah terendah (region minima)

b) Titik yang merupakan tempat dimana jika setetes air dijatuhkan, maka air tersebut akan akan jatuh ke sebuah posisi minimum (titik air=piksel, yang akan menuju titik minumum (catchmen basins))

c) Titik yang merupakan tempat dimana jika air akan dijatuhkan maka air tersebut mempunyai kemungkinan untuk jatuh kesalah satu posisi minimum Pengujian hasil segmentasi akan menggunakan metoda SNR(Signal Noise to Ratio).

Pada dasarnya untuk setiap hasil pengolahan citra medis dibutuhkan kontrol kualitas citra dan salah satu parameter kontrol untuk kualitas citra pada MRI dengan menghitung SNR. Pada dasarnya intensitas sinyal yang digunakan pada MRI menhasilkan noise salah satu penyebab dari fluktuasi acak arus pada koil penerima, oleh karena itu noise ini akan berpengaruh terhadap kualitas citra yang dihasilkan [2]. Perhitungan menggunakan metoda SNR yang digunakan adalah dengan menghitung dan membandingkan banyaknya piksel yang ada pada citra [11].

\section{Bahan dan Metoda}

Prosedur penelitian yang dilakukan pada penelitian ini terdiri dari beberapa tahapan 
secara umum yaitu percobaan pertama menguji gambar pencitraan medis tumor otak menggunakan teknik segmentasi watershed dengan 2 filter yang berbeda, yang pertama gambar akan diuji menggunakan filter sobel dan yang kedua filter menggunakan filter morphological gradient dengan dikombinasikan segmentasi watershed makers. Kedua hasil prosesing ini akan diuji berdasarkan kualitas citra menggunakan perhitungan SNR (Signal Noise to Ratio). Dalam penelitian ini dibutuhkan perangkat yang akan digunakan untuk menjalankan penelitian diantaranya perangkat keras hardware : PC (Personal Computer), Prosesor Intel Atom, RAM 1 GB atau Perangkat Lunak Software (Pemograman Python dan Library Simple ITK
Operating System Linux 14.0 LTS).

Percobaan pertama seperti yag ditunjukan oleh Gambar 2.2 proses ini menggunakan citra medis MRI otak dengan resolusi $512 \times 512$ dengan masing - masing 5 citra medis dari penampang yang berbeda citra yang digunakan ialan potongan Axial, Koronal dan Sagital. Proses pertama ialah dengan menambahkan proses smoothing gausian dengan sigma 0.4 untuk menghilangkan noise. Proses segmentasi watershed digunakan setelah melalui proses pendeteksian tepi menggunakan filter sobel menggunakan operator sobel $3 \times 3$ secara konvolusi Gambar 2.1 .

\begin{tabular}{|l|l|l|}
\hline-1 & 0 & 1 \\
\hline-2 & 0 & 2 \\
\hline-1 & 0 & 1 \\
\hline
\end{tabular}

(a) Mask Vertikal

\begin{tabular}{|c|c|c|}
\hline-1 & -2 & -1 \\
\hline 0 & 0 & 0 \\
\hline 1 & 2 & 1 \\
\hline
\end{tabular}

(b) Mask Horisontal

Gambar 2.1 Operator Sobel 3x3 
Berikut adalah diagram alir pecobaan pertama

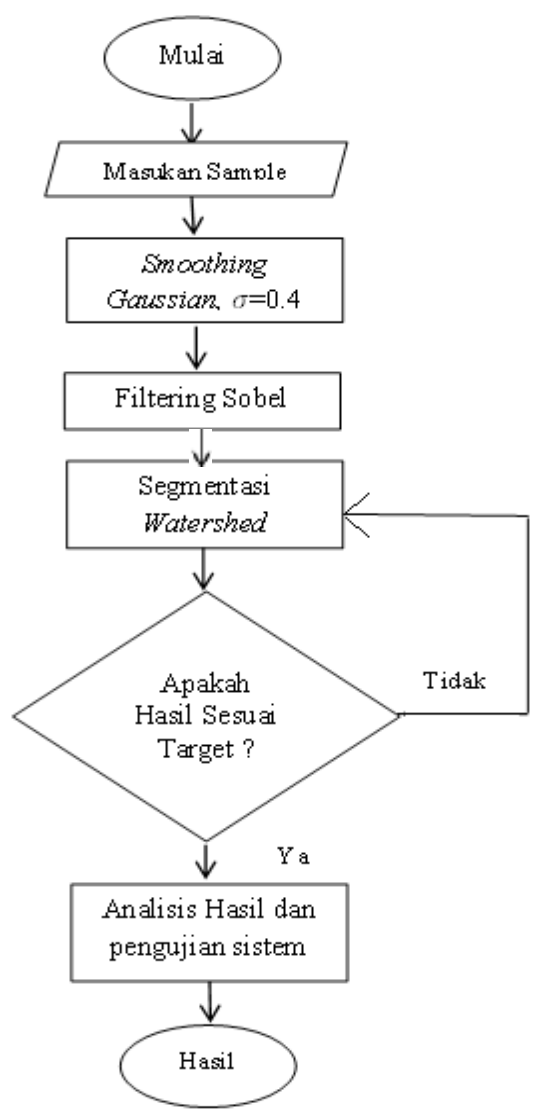

Gambar 2.2 Diagram Alir Prosedur Percobaan Pertama

Prosedur percobaan kedua ditunjukan oleh gambar diagram alir Gambar 2.3 sama seperti prosedur percobaan pertama teknik segmentasi watershed makers kombinasi dengan morphological gradient hasil ini kemudian akan dibandingkan dengan hasil prosedur percobaan pertama dengan menilai hasil uji kualitas citra. menggunakan persamaan berikut :

$$
S N R=10 . \log _{10}\left[\frac{\sum_{0}^{n_{x-1}} \sum_{0}^{n_{y-1}}[r(x, y)]^{2}}{\sum_{0}^{n_{x-1}} \sum_{0}^{n_{y-1}}[r(x, y)-t(x, y)]^{2}}\right]
$$




$$
\begin{aligned}
& n_{x} \quad \text { : Panjang citra (dalam piksel) } \\
& n_{y} \quad \text { : Lebar citra (dalam piksel) } \\
& \text { Keterangan : }(x, y) \text { : Kordinat masing masing piksel } \\
& r \quad \text { : Nilai intesitas citra asli } \\
& t \quad \text { : Nilai intensitas citra hasil }
\end{aligned}
$$

berikut adalah diagram alir prosedur percobaan ke-dua

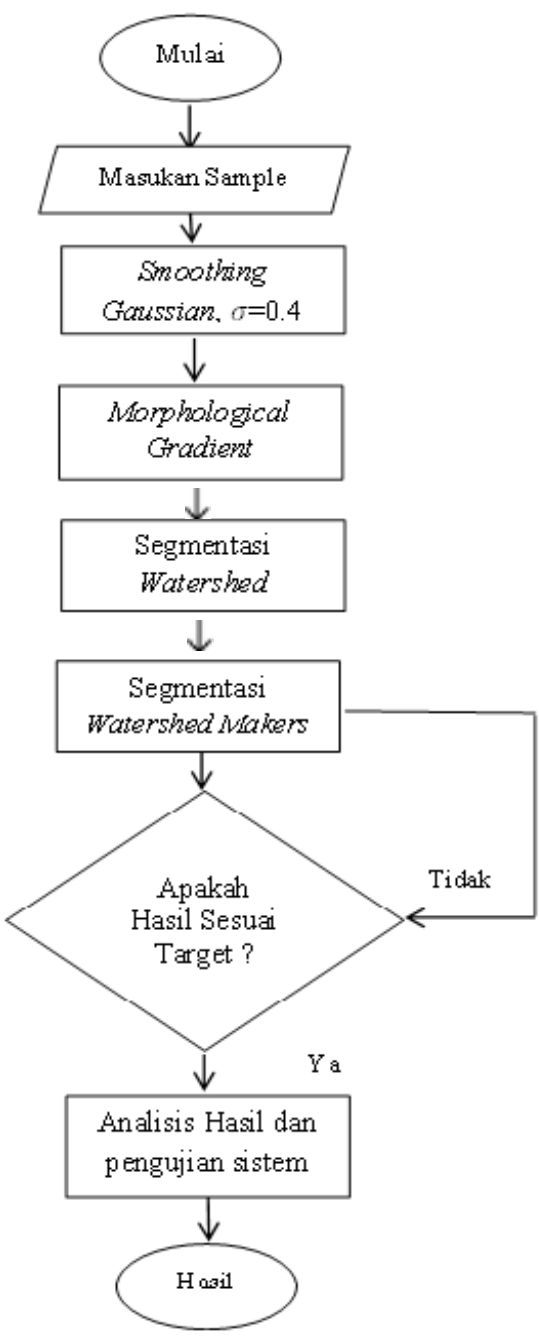

Gambar 2.3 Diagram Alir Prosedur Percobaan ke-dua

3. Hasil Dan Pembahasan

Segmentasi

watershed

telah

dikenal sebagai metoda yang

cukup efektif namun terjadi

beberapa

efek yang

menimbulkan kelemahan proses segmentasi ini yaitu terjadinya segmentasi yang berlebihan (oversegmentation). 
Pada dasarnya konsep dari segmentasi ini adalah menjadikan gambar sebagai bidang

topografi yang mempunyai tinggi dan rendah pada sebuah permukaan citra, efek oversegmentasi terjadi dikarenakan konsep lain yang mendasari segmentasi ini adalah dengan merepresentasikan air hujan yang jatuh diatas permukaan bidang topografi dan akan menelusuri tiap daerah yang ia lewati, oleh karena itu akan banyak region yang tersegmentasi. Parameter lain yang diuji ialah menggunakan level segmentasi dari level 7,9,11,13 dan 15 . Pengujian kualitas citra di gunakan setelah proses segmentasi berakhir, output dari hasil segmentasi ini ialah berbentuk gambar. Pengujian kualitas citra menggunakan perhitungan SNR (Signal Noise to Ratio). Hasil segmentasi watershed menggunakan filter sobel, tidak mampu mengurangi oversegmentasi yang terjadi ditunjukan oleh gambar 1 pada Tabel 3.1 pada hasil segmentasi watershed menggunakan filter sobel terhadap gambar hasil citra yang belum sempurna menunjukan segmentasi citra yang belum cukup akurat. Deteksi tepi yang dihasil oleh filter sobel terhadap piksel pada gambar berupa intensitas dimana akan mempengaruhi nilai piksel disekitarnya lebih tajam, sehingga pada proses segmentasi akan mengikuti batas tapi yang kurang akurat. Hasil lain ditunjukan oleh citra MRI lain dari slice yang berbeda dengan level 13 ditunjukan pada Tabel 3.2 menunjukan hasil yang sama dengan segmentasi terbaik diberikan oleh teknik segmentasi menggunakan kombinasi watershed makers dan morphological gradient. 
Tabel 3.1 Hasil Segmentasi Watershed Level 13

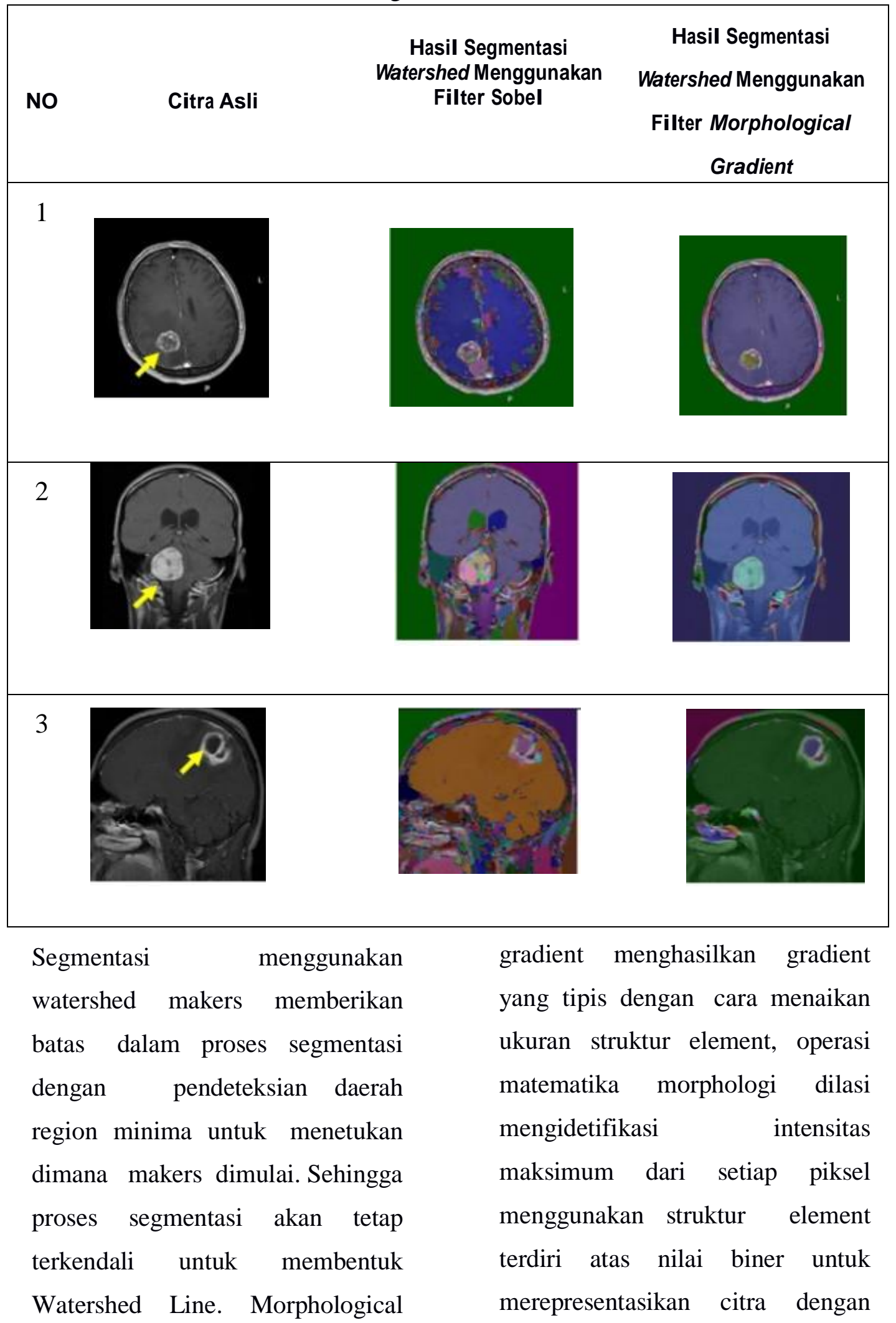


nilai 1 sebagai nilai maksimum titik yang rendah atau minimum. atau puncak dan nilai 0 sebagai

Tabel 3.2 Hasil Segmentasi Watershed Dengan Citra yang berbeda

\begin{tabular}{|c|c|c|}
\hline No & $\begin{array}{c}\text { Hasil Segmentasi } \\
\text { Watershed } \\
\text { Menggunakan Filter } \\
\text { Sobel }\end{array}$ & $\begin{array}{c}\text { Hasil Segmentasi } \\
\text { Watershed } \\
\text { Menggunakan Filter } \\
\text { Morphological } \\
\text { Gradient }\end{array}$ \\
\hline 2 & & 0 \\
\hline
\end{tabular}


Intensitas piksel pada setiap gambar juga yang mempengaruhi hasil segmentasi, pada bidang vertikal dan horizontal untuk mendapatkan nilai puncak dari sebuah gambar karena semakin tinggi intensitas dari piksel itu maka akan ditandai dengan warna putih sebagai puncak dari topografi pada citra abu, titik dimana piksel akan diurutkan berdasarkan nilainya dan membentuk sebuah daerah yang diinginkan. Hasil pengujian kualitas citra menggunakan metoda SNR (Signal Noise to Ratio) menghasikan rata - rata nilai SNR untuk kombinasi segmentasi watershed dan morphological gradient memperoleh nilai rata rata untuk setiap slice adalah axial 5.73 $\mathrm{dB}$, koronal $6.38 \mathrm{~dB}$ dan sagital $5.96 \mathrm{~dB}$ dengan waktu rata-rata komputasi adalah $1.20 \mathrm{~s}$ jika dibandingkan dengan kombinasi segmentasi menggunakan filter sobel yaitu untuk masing-masing slice adalah axial $5.68 \mathrm{~dB}$, koronal $6.28 \mathrm{~dB}$, dan sagital $5.27 \mathrm{~dB}$ dengan waktu rata-rata komputasi adalah 1.80 s. Berdasarkan hasil perhitungan ini nilai rata-rata SNR untuk setiap citra dengan nilai tertinggi di berikan oleh hasil segmentasi menggunakan kombinasi watershed makers dan morphological gradient ini membuktikan bahwa saat nilai SNR lebih besar menunjukan bahwa kualitas citra yang diperoleh oleh gambar tersebut semakin bagus.

\section{Simpulan}

Segmentasi tumor otak dari hasil citra MRI ini berhasil dilakukan dengan menggunakan preprossessing filter sobel, dan kombinasi morphological gradient segmentasi watershed markers untuk mengurangi efek segmentasi berlebihan. Dari 2 metoda yang digunakan metoda dengan menggunakan kombinasi watershed markers dan morphological gradient menghasilkan citra yang lebih baik dengan mengurangnya efek segmentasi berlebih dengan terjadi dengan mempertegas hasil output citra yang dihasilkan. Hasil pengujian kualitas citra menggunakan metoda SNR (Signal Noise to Ratio) menghasikan rata - rata nilai SNR untuk kombinasi segmentasi 
watershed dan morphological gradient memperoleh nilai rata rata untuk setiap slice adalah axial 5.73 $\mathrm{dB}$, koronal $6.38 \mathrm{~dB}$ dan sagital $5.96 \mathrm{~dB}$ dengan waktu rata-rata komputasi adalah $1.20 \mathrm{~s}$ jika dibandingkan dengan kombinasi segmentasi menggunakan filter sobel yaitu untuk masing-masing slice adalah axial $5.68 \mathrm{~dB}$, koronal $6.28 \mathrm{~dB}$, dan sagital $5.27 \mathrm{~dB}$ dengan waktu rata-rata komputasi adalah $1.80 \mathrm{~s}$.

\section{Referensi}

[1] Al-Tamimi., Mohammed

Sabbih Hamoud., \&

Ghazali Sulong., 2014,

Tumor Brain Detection

Thorugh MR Images A review of Literature , Journal of Theoretical and Applied Information Technology, vol. 6, no.2. Alan Tanjung Aji Prastowo., Wahyu

Setiabudi, Choirul Anam., 2012, Korelasi Nilai Time Repeatation (TR) dan Time Echo (TE) Terhadap Signal to Noise Ratio, Jurnal Fisika Undip, vol. 16, no. 4, pp. 103-110.
[3] Bairagi.V.K., Sapkal.A.M., 2013. ROI based DICOM image compression for telemedicine.

Sadhana 38, 123131.

[4] Balafar, M., Ramli A., Saripan M., \& Mashohor., 2010, Review of Brain MRI Segmentation Methods , Atrificial Intelegence Review 33, 261-274.

[5] Beucher., F, Meyer., 1993, The Morphological Approach to Segmentation: The Watershed Transformation. Centre de Morphologie Mathematique Ecole Des Mines de Paris, Fontaina bleaus, France.

[6] Diah Priyawati., Indah Soesanti., \& Indriana Hidayah., 2015. Kajian Pustaka Metoda

Segmentasi Citra Pada MRI Tumor Otak, Prosiding SNST

[7] Gunawan., Fandi Halim., \& Evni Wijaya., 2011, Perangkat lunak Segmentasi Citra dengan Metoda 
Watershed, JSIFO STMIK

Mikroskil, Vol. 12 no. 2 , ISSN

1412-0100.

[8] Murinto., \& Agus.H., 2009,

Segementasi Citra

Menggunakan Watershed dan

Intensitas

Filtering Sebagai Pre-

Prosesing Seminar Nasional

Informatika ( semnasIF).

Yogyakarta ISNN:1979-2328

[9] Ning Li., Miaomio Liu., \&

You fu Li., 2007, Image

Segementation Algorithm

Using Watershed Transform

Level set Method,

International Conference on

Acoustics Speech and Signal

Processing, (ICASSP) IEEE,

pp 613616.

[10] Rudi Adi Pranata.,

2005, Kombinasi

Metode Morphological

Gradient dan

Transformasi

Watershed pada Proses

Segemtasi Citra Digital.

Skripsi, Universitas

Kristen, Surabaya.

[11] Rafael.C.Gonzales., \&

Richard.E.Woods., 2012,

Digital Image Processing. New

Jersey: Prentice hall. 